\title{
Design of Low Energy Integrated Membranes Units for Production of Highly Purified Water
}

\author{
H. Abdallah ${ }^{1}$, M. S. Shalaby ${ }^{1}$, A. M. Shaban ${ }^{2}$ \\ ${ }^{1}$ Chemical Engineering and Pilot Plant Department, Engineering Research Division, National Research Centre, Egypt \\ ${ }^{2}$ Water Pollution Research Department, Environmental Pollution Research Division, National Research Centre, Egypt \\ Email: heba_nasr94@yahoo.com
}

\begin{abstract}
Some industries like medical, pharmaceuticals, cosmetics, chemical manufacturing need a special quality of treated water which is called Purified water. Integrated membrane system was designed and developed to produce Purified water grades to serve these industries. A simple engineering design for water filtration through membrane systems was scanned; beginning from carbon filters, followed by different kinds of membranes like microfiltration, ultrafiltration, nanofiltration and reverse osmosis membrane. These units were developed according to membranes type and the produced water quality before and after each unit. The Produced water and its quality control tests were compared with the World Health Organization water quality standard. The produced water from the integrated membrane system has TDS reached $0.95 \mathrm{mg} / \mathrm{L}$, which matched with the World Health Organization water quality standard.

Keywords: purified water, membranes system, quality control, ultrafiltration, microfiltration, nanofiltration, reverse osmosis
\end{abstract}

\section{Introduction}

There are different kinds of filtration techniques that can be used to produce the different grades of pure and ultrapure water required for advanced and precise industries such as pharmaceutical food industries and for laboratory analysis using ${ }^{[1-5]}$. Pure water can be defined in terms of various parameters, including resistivity, microorganism content, pyrogen (endotoxins) levels, reactive silica levels and total organic carbon (TOC) levels ${ }^{[1-4]}$. There are at least five grades of pure water depending on various standards and conventions, which are illustrated in Table $1^{[1-3]}$. Each grade of pure water can be used in a number of various applications such as ${ }^{[1]}$ :

- Deionized water: used for medium pressure boiler feed, renal dialysis make-up, and battery top-up.

- Purified water: Used for pharmaceuticals, cosmetics, chemical manufacturing.

- Pyrogenic water: Used for vial washing, tissue culture, water for injections.

- High Purity water: Used for high-pressure boilers, combined heat and power systems, laboratories.

- Ultrapure water: used for microelectronics, supercritical boilers.

The most commonly used technologies for water treatment to reach different water treatment grade are membranes, ultraviolet (UV) emission technology, ion exchange technologies ${ }^{[3-8]}$.

The use of ultraviolet (UV) emission technology is widespread in pure water production, especially, for application needs water with low total organic carbon levels, such as in purified, pyrogenic and ultrapure water applications. Research and development over recent years have shown that short wavelengths (190-195nm) are highly effective at breaking down organic molecules present in pure water, especially low molecular weight contaminants. UV systems are also used for disinfection, dechlorination, and de-ozonation within pure water treatment processes. Several of the process stages in the manufacture of pharmaceutical products can cause downstream microbial contamination, however, UV can be used as an effective barrier to ensure these microbes remove to do not compromise overall quality requirements ${ }^{[1,17,20,21]}$. Ion exchange technologies are needed for producing high purity water. They also offer the possibility of developing noncorrosive processes due to their eco-friendly nature. Regeneration and handling are the main problems of these units ${ }^{[1-3]}$. RO membranes systems combined with other technologies is now the preferred main treatment option in Purified Water production. This is due to many reasons including the security of combination, the TOC limit, easy handling of chemicals and effluent, and microbiological quality ${ }^{[1,18]}$.

Copyright (C)2020 H. Abdallah, et al.

DOI: https://doi.org/10.37256/aecm.112020129

This is an open-access article distributed under a CC BY license

(Creative Commons Attribution 4.0 International License)

https://creativecommons.org/licenses/by/4.0/ 
Activated carbon is used to purify liquids and gases in a variety of applications, including municipal drinking water, food and beverage processing, odor removal, industrial pollution control, and point-of-use filters in the houses. Activated carbon filter contains three regions: Micropore region-less than 100 Angstroms, Mesopore region-between 100 and 1,000 Angstroms and Macropore region - greater than 1,000 Angstroms.

The contaminants in the water are adsorbed onto the surface of carbon from water due to differences in adsorbate concentration in the feed water and in the carbon pores. The dissolved adsorbate transfer from the solution through the pores channels to reach the area where the strongest attractive forces are located. Besides, physical adsorption chemical reactions can occur on a carbon surface. One such reaction is chlorine removal from water involving the chemical reaction of chlorine with carbon to form chloride ions.

Recently, membrane technology is considered to be a significant way to produce different grades of pure water, according to the feeding water. Treating water using membranes can be performed by using integrated membranes unit ${ }^{[9-15]}$.

Membrane-based processes are widely used for desalination and water treatment. Microfiltration (MF), ultrafiltration (UF), nanofiltration (NF), and reverse osmosis (RO) are the most kinds of membrane technologies. Enhancement of permeate flux, rejection percentage, and antifouling properties are necessary to improve the efficiency of these processes. Ultrafiltration (UF) or microfiltration (MF) technology can be effectively used as a pre-treatment for reverse osmosis (RO) depending on the feeding water quality to the water treatment system. Microfiltration can remove materials such as sand, silt, clays, Giardia lamblia and Cryptosporidium cysts, algae, and some bacterial species. The deionized water can be easily produced using single-pass RO systems as the final process step with using high rejection (HR) membranes. RO is a cross-flow membrane separation process providing a level of filtration down to ionic levels for removal of dissolved salts ${ }^{[10-18]}$. According to the feeding water quality RO membranes can be formed in an array system to give an overall concentrate stream flow as low as $10 \%$ of the feeding supply, equating to an overall system recovery of up to $90 \%$. The salts in the water feeding supply will be concentrated in the reject stream and must be treated by subsequent processes onsite or discharged to the sewerage system for further treatment. Individual RO membranes typically reject $95-98 \%$ of the total dissolved solids (TDS) in the feeding supply, which will reduce the ionic loading onto downstream processes. Also, UF and MF membrane technology can be used for the final polishing of pure water and removal of bacterial endotoxins, bacteria, particles in pharmaceutical pyrogenic and semiconductor applications ${ }^{[3,7,19]}$.

The main goal of this article is the development and design of the integration of membranes filtration systems to produce purified water from different water sources.

In the article we studied production of highly purified water which can be used in labs as alternative of distillatory and deionizer using integrated membranes units, so the heating or requirement of excessive treatment for the traditional apparatuses like distillatory and deionizer, that made our system low energy.

\section{Experimental work}

\subsection{Determination of water source and analysis}

The samples were taken from five places of NRC, Building of Scientific Excellence, Engineering Research Division, Textile Industries Research Division, The Main Building, and the Agricultural Research Division. The samples were taken from 1/10/2016 to 1/6/2017. The tap water samples were collected in clean and dry glass bottles. Each sample was filtered using Whatman no.42 filter paper and stored in the refrigerator until the analysis time. The analyses of samples were carried out using Agilent ICP -5100 in NRC labs. The TDS and electrical conductivity of the water samples were measured at room temperature using a conductivity meter called Adwa (AD 310), EC/temp meter made in Romania. The pH of water samples also was measured using a Jenway $\mathrm{pH}$ meter made in England. The turbidity of the samples was measured by the turbidity meter model Hanna made of Boland.

\subsection{Design of different integrated lab system of membrane filtration}

Lab filtration systems were designed and installed to use our prepared membranes. First, the commercial filtration system was used and commercial membranes which were purchased from Aqua Chiara Company and studied preliminary experiments from tap water filtration. According to the results we designed five integrated systems to study the purity of water.

\subsubsection{Filtration experiments using commercial filtration system}

Tap water from the Building of Scientific Excellence was filtered using a commercial filtration system which purchased from Aqua Chiara Company to indicate the separation elements after each step in this filter as shown in Figure 1. This filter has a microfiltration unit, two activated carbon filters, reverse osmosis membrane and feeding pump with 
pressure 150 psi. The tap water firstly flows through the microfiltration unit then passes to the activated carbon units and finally goes to the reverse osmosis unit. Samples of water were collected after $1 \mathrm{~h}$ from each unit and analyzed. These experiments were carried out to help in the design and determination of the operating conditions.

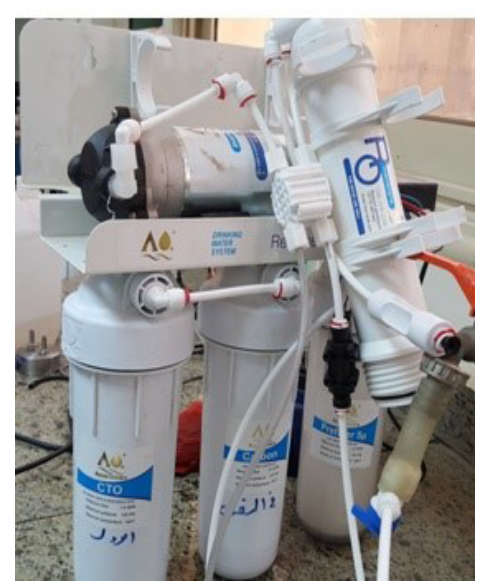

Figure 1. Commercial filtration unit

\section{Results \& Discussions}

\subsection{Determination of water source and analysis}

The analyzed results of the samples which were taken from different five places of NRC, Agricultural Research Division (B1), Building of Scientific Excellence (B2), Engineering Research Division (B3), Textile Industries Research Division (B4), and The main Building (B5), were taken from 1/10/2016 to 1/6/2017 were drawn by Pivot table Using Microsoft Office Excel as shown in Table 1. Table 2 illustrates the physical parameters for average analysis of water samples. Also, the statically analysis of these results was studied as shown in Table 3. Figure 2 illustrates the ions percentage in different water samples, where the di-ions are the highest ions in the samples, that means the nanofiltration membrane can be used in our design to remove divalent ions before reverse osmosis membrane.

The limit of $\mathrm{pH}$ value for drinking water is specified as 6.5 to 8.5 . While $\mathrm{pH}$ value in the studied tap water from a different place of NRC varied from 7 to 7.18. So, the $\mathrm{pH}$ value is in the limit of drinking water. Increasing $\mathrm{pH}$ provides a bitter taste to water, and causes corrosion for equipment. According to ASTM D1193-06, purified water $\mathrm{pH}$ is range 5-8 ${ }^{[2]}$.

The total hardness is mostly high in all samples due to the presence of magnesium, iron, chloride and sodium ions. The high amount of hardness in water that can lead to heart diseases and kidney stone formation. Hardness value in the samples varied between $109-117 \mathrm{mg} / \mathrm{L}$. According to ASTM D1193-06, purified water hardness must be less than 70mg/1 ${ }^{[2]}$. 
Table 1. Average results of chemical parameters of water samples from different places of NRC

\begin{tabular}{|c|c|c|c|c|c|c|}
\hline Values(average)(mg/L) & B1 & B2 & B3 & B4 & B5 & Accepted limit \\
\hline Chloride & 35.5 & 36.5 & 34.5 & 34.5 & 35 & $<250$ \\
\hline Sulphate & 31 & 32 & 34 & 32 & 33 & $<250$ \\
\hline Total Hardness & 109 & 117 & 112 & 110 & 109 & $<500$ \\
\hline Potassium & 4.305 & 4.17 & 7.89 & 4.535 & 4.735 & $<10$ \\
\hline Sodium & 29.65 & 30.6 & 30.76 & 28.5 & 27.58 & $<200$ \\
\hline Magnesium & 8.8 & 10.25 & 8.85 & 7.85 & 7.65 & $<36$ \\
\hline Calcium & 27.75 & 29.125 & 27.25 & 29.7 & 30.4 & $<140$ \\
\hline Boron & 0.01 & 0.085 & 0.07 & 0.01 & 0.01 & $<0.5$ \\
\hline Strontium & 0.055 & 0.15 & 0.28 & 0.045 & 0.04 & $<0.5$ \\
\hline Iron & 0.0001 & 1.815 & 1.175 & 0.0001 & 0.0001 & $<0.3$ \\
\hline Aluminum & 0.12 & 0.28 & 0.39 & 0.025 & 0.14 & $<0.2$ \\
\hline Manganese & 0 & 0.01 & 0.02 & 0 & 0.01 & $<0.4$ \\
\hline Nickel & 0 & 0 & 0.01 & 0 & 0 & $<0.02$ \\
\hline Zinc & 0 & 0.33 & 2.64 & 0 & 0 & $<3$ \\
\hline Arsenic & 0.01 & 0 & 0 & 0 & 0.01 & $<0.01$ \\
\hline Barium & 0 & 0 & 0.06 & 0 & 0 & $<0.7$ \\
\hline
\end{tabular}

Where, Agricultural Research Division (B1), Building of Scientific Excellence (B2), Engineering Research Division (B3), Textile Industries Research Division (B4), and The main Building (B5)

Table 2. Average results of physical parameters of water samples from different places of NRC

\begin{tabular}{|c|c|c|c|c|c|c|}
\hline Values (average) & B1 & B2 & B3 & B4 & B5 & $\begin{array}{c}\text { Accepted } \\
\text { limit }\end{array}$ \\
\hline Turbidity (NTU) & 0.33 & 6.7 & 7.1 & 0.34 & 0.41 & $<1$ \\
\hline TDS (mg/L) & 221.5 & 211.5 & 213.5 & 241 & 225 & $<1000$ \\
\hline TSS (mg/L) & 0.3 & 9 & 10 & 0.3 & 0.2 & $<100$ \\
\hline Conductivity $(\mu \mathrm{s} / \mathrm{cm})$ & 452.5 & 438 & 462.5 & 495.5 & 459 & $<1200$ \\
\hline $\mathrm{COD}(\mathrm{mg} / \mathrm{L})$ & 3 & 4.5 & 4 & 2.75 & 3 & $<250$ \\
\hline $\mathrm{pH}$ & 7.03 & 7.475 & 7.525 & 6.925 & 6.975 & $6.5-8.5$ \\
\hline
\end{tabular}

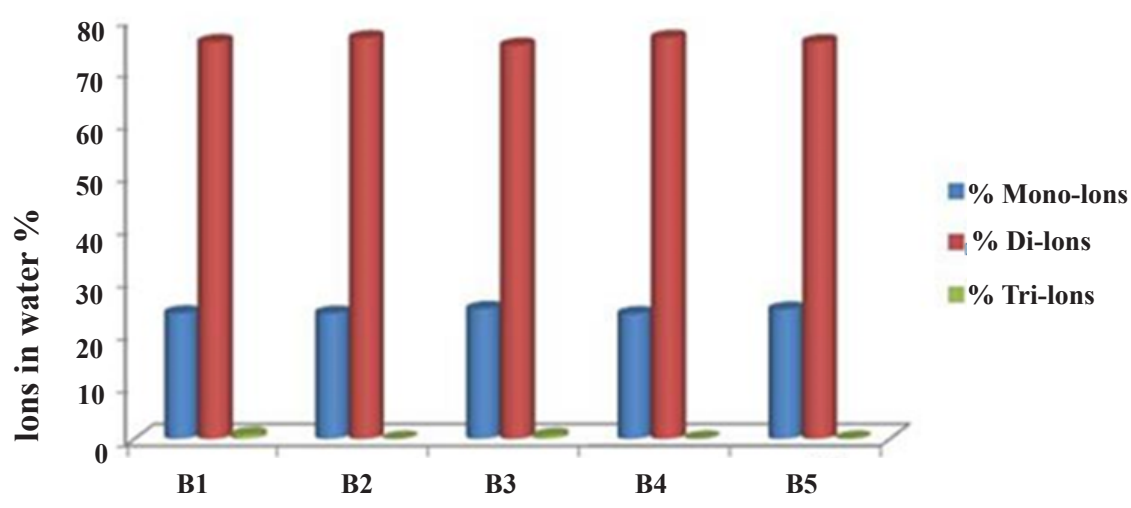

Figure 2. Average percentage of ions on water samples

The iron value in the water samples varied between $0-1.8 \mathrm{mg} / \mathrm{L}$. In European pharmacopeia, iron in purified water must be less than 0.1 , while at the US Pharmacopeia iron must be zero ${ }^{[1]}$.

$\mathrm{COD}$ in the water samples varied between $3-4.5 \mathrm{mg} / \mathrm{L}$. COD means that there is inadequate oxygen available in the water samples due to the oxidizable inorganic matter. In European pharmacopeia, the COD must be less than 0.5 and for high purity water must be zero\%.

Electrical conductivity (EC) of water is a direct function to the total dissolved salts in water and an indication for 
ions in the water. The conductivity value of the water samples varied between 438 to $462.5 \mu \mathrm{S} / \mathrm{cm}$. If water has high conductivity, this means the presence of a high amount of dissolved inorganic substances in the ionized form ${ }^{[1]}$. EC in European pharmacopeia must be $0.6-4.7 \mu \mathrm{S} / \mathrm{cm}$.

High values of TDS in the water samples may affect persons who are suffering from kidney and heart diseases. A high content of dissolved solids leads to the density of water, influences osmoregulation of freshwater organism, reduces the solubility of gases (like oxygen) and decrease the solubility of water for drinking, irrigation, and industrial purposes. TSS and TDS values in the water samples varied between $0.3-10 \mathrm{mg} / \mathrm{L}$, and $221-241 \mathrm{mg} / \mathrm{L}$ respectively. In purified water for analyzed purified water, the TDS must be less than $1 \mathrm{mg} / \mathrm{L}$ at US Pharmacopeia ${ }^{[1]}$.

\subsection{Correlation studies}

Interrelationship studies between various water quality parameters are very useful in understanding geochemistry of the studied region of water. The regression equations for the parameters contain significant correlation coefficients which can estimate the concentration of other constituents. Table 3(a) illustrates Correlation coefficient values for total hardness with the influencing elements effect on it. Where, the total hardness indicates significant correlation with chloride, magnesium, sodium, and iron due to the effect of their salts in water. Table 3(b) indicates that the turbidity significant correlation with sodium, magnesium, iron, boron, and aluminum. Table 3(c) illustrates that TSS has a significant correlation with sodium, magnesium, boron, iron, aluminum, strontium and manganese, where their salts increase the total suspended solids. Table 3(d) indicates that COD has a significant correlation with sodium, magnesium, boron, iron, aluminum, strontium and manganese due to the oxidability of these inorganic elements ${ }^{[1,5]}$.

Table 3. Correlation Coefficient Values of various Physico- Chemical Parameters of Water samples from NRC various places.

(a) Total Hardness and their influencing elements

\begin{tabular}{crrrr}
\hline & Chloride & Sodium & Magnesium & Total Hardness \\
\hline Chloride & 1 & & & \\
Sodium & 0.366614842 & 1 & & \\
Magnesium & 0.794987874 & 0.845045509 & & \\
Iron & 0.540622707 & 0.801383325 & 0.869738965 & 1 \\
Total Hardness & 0.675562228 & 0.683619915 & 0.882285967 & 0.951506988 \\
\hline
\end{tabular}

(b) Turbidity and their influencing elements

\begin{tabular}{|c|c|c|c|c|c|c|}
\hline & Sodium & Magnesium & Boron & Iron & Aluminum & $\begin{array}{r}\text { Turbidity } \\
\text { (NTU) }\end{array}$ \\
\hline Sodium & 1 & & & & & \\
\hline Magnesium & 0.845046 & 1 & & & & \\
\hline Boron & 0.828442 & 0.830080788 & 1 & & & \\
\hline Iron & 0.801383 & 0.869738965 & 0.991927 & 1 & & \\
\hline Aluminum & 0.765565 & 0.598753725 & 0.866444 & 0.809044 & 1 & \\
\hline Turbidity (NTU) & 0.839697 & 0.747606159 & 0.98346 & 0.952578 & 0.925435334 & 1 \\
\hline
\end{tabular}


(c) TSS and their influencing elements

\begin{tabular}{|c|c|c|c|c|c|c|c|c|}
\hline & Sodium & Magnesium & Boron & Iron & Aluminum & Strontium & Manganese & TSS \\
\hline Sodium & 1 & & & & & & & \\
\hline Magnesium & 0.845045509 & 1 & & & & & & \\
\hline Boron & 0.828442262 & 0.830080788 & 1 & & & & & \\
\hline Iron & 0.801383325 & 0.869738965 & 0.991927 & 1 & & & & \\
\hline Aluminum & 0.76556539 & 0.598753725 & 0.866444 & 0.809044 & 1 & & & \\
\hline Strontium & 0.799596865 & 0.49594833 & 0.821419 & 0.742771 & 0.937879621 & 1 & & \\
\hline Manganese & 0.443348181 & 0.254859501 & 0.696022 & 0.623608 & 0.905945789 & 0.851562424 & 1 & \\
\hline TSS & 0.847261085 & 0.736556537 & 0.977524 & 0.942918 & 0.929167572 & 0.922918946 & 0.787418363 & 1 \\
\hline
\end{tabular}

(d) COD and their influencing elements

\begin{tabular}{|c|c|c|c|c|c|c|c|c|}
\hline & Sodium & Magnesium & Boron & Iron & Aluminum & Strontium & Manganese & COD \\
\hline Sodium & 1 & & & & & & & \\
\hline Magnesium & 0.845045 & 1 & & & & & & \\
\hline Boron & 0.828442 & 0.830080 & 1 & & & & & \\
\hline Iron & 0.801383 & 0.869738965 & 0.991927 & 1 & & & & \\
\hline Aluminum & 0.765569 & 0.598753725 & 0.866444 & 0.809044 & 1 & & & \\
\hline Strontium & 0.7995968 & 0.49594833 & 0.821419 & 0.742771 & 0.937879621 & 1 & & \\
\hline Manganese & 0.4433481 & 0.254859501 & 0.696022 & 0.623608 & 0.905945789 & 0.851562424 & 1 & \\
\hline COD & 0.8067208 & 0.873159179 & 0.986431 & 0.990389 & 0.857437397 & 0.758211693 & 0.669893845 & 1 \\
\hline
\end{tabular}

\subsection{Design of different integrated lab system of membrane filtration}

\subsubsection{Filtration experiments using the commercial filtration system}

Tap water from the Building of Scientific Excellence (NRC) was filtered using a commercial filtration system to indicate the separation elements after each unit as shown in Table 4. The system consists of microfiltration membrane, two activated carbon filters and Reverse osmosis membrane. The analysis of water was recorded after each step and compared with feeding water from the center of excellence labs.

\subsubsection{Microfiltration step}

The first step is Microfiltration where the Microfiltration is a membrane with a pore size of approximately 0.03 to 10 microns; in this case, the pore size of the membrane is $5 \mu \mathrm{m}$. It was worked at low feed water operating pressure of approximately 100 to $400 \mathrm{kPa}$ (15 to $60 \mathrm{psi}$ ). Microfiltration can remove materials such as sand, silt, clays, Giardia lamblia and Cryptosporidium cysts, algae, and some bacterial species. Accordingly, MF can control the microorganisms in water. MF can be used as a pretreatment to RO or NF to reduce fouling potential. Table 4 indicates the analysis of water after the microfiltration step. The results indicated that using commercial microfiltration membrane to treat tap water reduce turbidity from 6.7 NTU to 1 NTU, which means the colloidal materials, bacteria and any suspended materials were separated by $85 \%$. But total suspended solids (TSS) decreased from $9 \mathrm{mg} / \mathrm{L}$ to $8 \mathrm{mg} / \mathrm{L}$, (11\% separation percentage) which was a very low percentage of separation.

\subsubsection{An activated carbon step}

The experiments were carried out, where the water passes through microfiltration firstly and two activated carbon filters secondly. Table 4 indicates the analysis of water after activated carbon filters and compared with feeding water in the center of the excellence lab. The experiments result indicated that all analysis of water elements had a high percentage, where the turbidity decreased than feed (6.7 NTU) to be $1.45 \mathrm{NTU}$ after first activated carbon and 1.15 after second activated carbon.

\subsubsection{Reverse osmosis membrane}

Reverse osmosis can effectively remove approximately all inorganic contaminants from water. RO can also effectively remove all contamination from water. But it is more effective when used in series with multiple units ${ }^{[15-20]}$. 
The experiments were carried out, where the water passes through micro filtration firstly and two activated carbon filters secondly and finally RO unit.

Table 4 indicates that the elements of water decreased after the RO membrane. The hardness as calcium and magnesium were removed completely. But removing sodium was $50 \%$ and TDS separation was from 203 to $51 \mathrm{mg} / \mathrm{L}$ which means $75 \%$ separation percentage. To reach purified water which can be used in research studies TDS must be less than $1 \mathrm{mg} / \mathrm{L}$.

Table 4. Analysis of water after treatment by commercial filtration system

\begin{tabular}{|c|c|c|c|c|c|c|}
\hline Parameter & unit & Tap water & After MF & After AC1 & After AC2 & $\begin{array}{c}\text { After RO } \\
\text { membrane }\end{array}$ \\
\hline Chloride & $\mathrm{mg} / \mathrm{L}$ & 27 & 27 & 27 & 27 & 20 \\
\hline Nitrate & $\mathrm{mg} / \mathrm{L}$ & ND & ND & ND & ND & $\mathrm{ND}$ \\
\hline Nitrite & $\mathrm{mg} / \mathrm{L}$ & ND & ND & ND & ND & ND \\
\hline Sulphate & $\mathrm{mg} / \mathrm{L}$ & 32 & 32 & 32 & 32 & 8 \\
\hline Bicarbonate & $\mathrm{mg} / \mathrm{L}$ & 102 & 100 & 100 & 100 & 28 \\
\hline Carbonate & $\mathrm{mg} / \mathrm{L}$ & 0 & 0 & 0 & 0 & 0 \\
\hline Total Hardness & $\mathrm{mg} / \mathrm{L}$ & 102 & 88 & 66 & 66 & 0 \\
\hline Silica & $\mathrm{mg} / \mathrm{L}$ & ND & ND & $\mathrm{ND}$ & ND & ND \\
\hline Potassium & $\mathrm{mg} / \mathrm{L}$ & 78 & 75 & 75 & 75 & 15 \\
\hline Sodium & $\mathrm{mg} / \mathrm{L}$ & 55 & 55 & 55 & 55 & 21 \\
\hline Magnesium & $\mathrm{mg} / \mathrm{L}$ & 7 & 5 & 4.8 & 4.7 & 0 \\
\hline Calcium & $\mathrm{mg} / \mathrm{L}$ & 26.5 & 26 & 18.4 & 18 & 0 \\
\hline Turbidity & NTU & 6.7 & 1 & 1.45 & 1.15 & 0.6 \\
\hline $\mathrm{pH}$ & & 7.2 & 7.1 & 8.5 & 9 & 7.5 \\
\hline $\mathrm{EC}$ & $\mathrm{ms}$ & 426 & 338 & 336 & 335 & 100 \\
\hline TDS & $\mathrm{mg} / \mathrm{L}$ & 203 & 183 & 180 & 178 & 51 \\
\hline COD & $\mathrm{mgO}_{2} / \mathrm{L}$ & 3 & 3 & 3 & 3 & 2 \\
\hline TSS & $\mathrm{mg} / \mathrm{L}$ & 9 & 8 & 8 & 8 & 0.02 \\
\hline Boron & $\mathrm{mg} / \mathrm{L}$ & 0.06 & 0.05 & 0.05 & 0.05 & 0.03 \\
\hline Strontium & $\mathrm{mg} / \mathrm{L}$ & 0.28 & 0.27 & 0.27 & 0.25 & 0.25 \\
\hline $\mathrm{Fe}$ & $\mathrm{mg} / \mathrm{L}$ & 1.2 & 1.2 & 1.1 & 1.1 & 0.65 \\
\hline $\mathrm{Al}$ & $\mathrm{mg} / \mathrm{L}$ & 0.45 & 0.45 & 0.44 & 0.43 & 0.1 \\
\hline $\mathrm{Mn}$ & $\mathrm{mg} / \mathrm{L}$ & 0.01 & 0.01 & 0.01 & 0.01 & 0.001 \\
\hline
\end{tabular}

\subsubsection{Design of integrated lab membranes filtration system}

The integrated system of membrane filters was designed, where the designed system has a pressure pump after ultrafiltration unit to increase the pressure for nanofiltration and reverse osmosis units.

Our prepared membranes were fabricated to reach the high quality of purified water. According to preliminary results for water treatment of tap water in the center of excellence labs (NRC) after commercial filtration system using commercial membranes. We have designed membrane-integrated systems to study the purity of water as shown in Figure 3 .

The integrated filtration system design composed of an Activated Carbon unit, Microfiltration unit, Ultrafiltration unit, Nanofiltration Unit and Reverse Osmosis Unit. The Design was built on the commercial applied size of membrane housing in the local market because spiral wound membranes were produced in standard size like commercial and imported spiral wound size, which is considered as international size. So, this can facilitate the application of these standard modules in this work. 


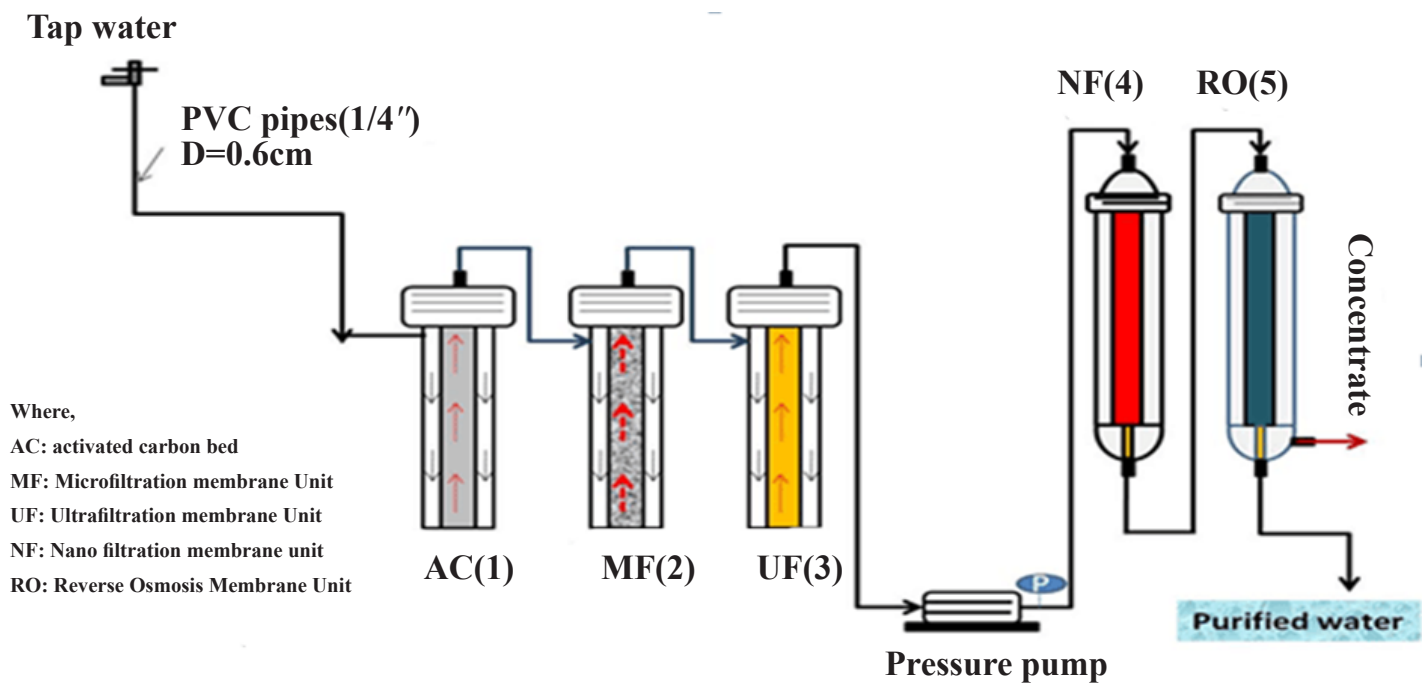

Figure 3. Schematic drawing for integrated membrane filtration system design for water purification

\subsubsection{Design concepts of membrane units}

There is a number of general concepts that are applicable to all kinds of pressure-driven membrane systems, which serve as the underlying basic principles of system design and operation. These concepts include flux, recovery and flow balance. Membrane filtration system productivity is typically characterized by the system flux, which is defined as the filtrate flow per unit of membrane filtration area, as shown in Equation $1^{[21-23]}$ :

$$
J=\frac{Q_{p}}{A_{m}}
$$

Where:

$J=$ flux $\left(\mathrm{L} / \mathrm{m}^{2} \cdot \mathrm{h}\right)$

$Q_{p}=$ filtrate flow $(\mathrm{L} / \mathrm{h})$

$A_{m}=$ membrane surface area $\left(\mathrm{m}^{2}\right)$

The recovery of a membrane unit is defined as the amount of feed flow that is converted to filtrate flow, expressed as a decimal percent, as shown in Equation 2:

$R=\frac{Q_{p}}{Q_{f}}$

Where: $R=$ recovery of the membrane unit $(\%)$

$Q_{p}=$ filtrate flow produced by the membrane unit $(\mathrm{L} / \mathrm{h})$

$Q_{f}=$ feed flow to the membrane unit $(\mathrm{L} / \mathrm{h})$

A general flow balance that can be applied to all membrane filtration systems is shown in Equation 3:

$Q_{f}=Q_{c}+Q_{p}$

Where: $Q_{f}=$ feed flow to the membrane unit $(\mathrm{L} / \mathrm{h})$

$Q_{c}=$ concentrate flow from the membrane unit $(\mathrm{L} / \mathrm{h})$

$Q_{p}=$ filtrate flow from the membrane unit $(\mathrm{L} / \mathrm{h})$

(a) Microfiltration and Ultrafiltration 
MF and UF are characterized according to the ability to separate suspended or colloidal particles through a sieving mechanism based on the size of the membrane pores relative to that of the particulate matter. However, Membranes have different pore size distribution depending on membrane materials and fabrication processes. MF membranes are generally having a pore size range of $0.1-10 \mu \mathrm{m}$ (nominally $0.1 \mu \mathrm{m}$ ). UF membranes pore sizes generally range from $20 \mathrm{~nm}-0.05 \mu \mathrm{m}{ }^{[21,}$ 22, 23].

The driving force for the water transport across a microporous membrane-like MF and UF is a pressure gradient across the membrane, or TMP, which is mean the pressure on the feed side of the membrane minus the filtrate pressure, generally called the backpressure, as shown in Equation 4:

$$
T M P=P_{f}-P_{p}
$$

Where: $T M P=$ transmembrane pressure (psi)

$P_{f}=$ feed pressure (psi)

$P_{p}=$ filtrate pressure (i.e., back pressure) (psi)

Using standard area of MF and UF filter was $378.84 \mathrm{~cm}^{2}$, feed pressure was $72.5-116 \mathrm{psi}$, filtrate pressure was approximately 69.6-114.5 psi, TMP was $2.9 \mathrm{psi}$ and flux was $46.4 \mathrm{~L} / \mathrm{m}^{2} . h$. According to the commercial filtration unit size, the microfiltration unit has a cylindrical shape with a diameter of $10 \mathrm{~cm}$ and length $28 \mathrm{~cm}$ with screw cap from the top of the housing and the material of construction of housing was reinforced PVC. In this design, UF membrane housing was the same as MF housing.

(b) Nanofiltration and reverse osmosis membranes

$\mathrm{NF} / \mathrm{RO}$ membranes were designed to separate dissolved solids through the process of reverse osmosis. The flow of solution continues until the chemical potentials (or concentrations, for practical purposes) on both sides of the membrane are equal. The pressure which must be applied to the more concentrated solution to stop this flow of water is called osmotic pressure $^{[24]}$.

In NF and RO processes driving force for water transport across a semipermeable membrane is a pressure gradient across the membrane. The producing osmotic pressure gradient from NF and RO which acts against the transport of water from the feed to filtrate side of the membrane should be taken into consideration. The net driving pressure (NDP) depending on TDS on the feed and filtrate sides of the membrane can be calculated using Equation 5:

$$
N D P=\left[\left(\frac{P_{f}+P_{c}}{2}\right)-\left(P_{p}\right)\right]-\left[\left\{\left(\frac{T D S_{f}+T D S_{c}}{2}\right)-T D S_{p}\right\} * 0.01\right]
$$

Where: $N D P=$ net driving pressure (psi)

$P_{f}=$ feed pressure (psi)

$P_{c}=$ concentrate pressure $(\mathrm{psi})$

$P_{p}=$ filtrate pressure (i.e., back pressure) (psi)

$T D S_{f}=$ feed TDS concentration $(\mathrm{mg} / \mathrm{L})$

$T D S_{c}=$ concentrate $T D S$ concentration $(\mathrm{mg} / \mathrm{L})$

$T D S_{p}=$ filtrate $T D S$ concentration $(\mathrm{mg} / \mathrm{L})$

Equation (5) represents the differences between the average pressures on the feed side of the membrane and the filtrate back pressure; the second term represents the average osmotic backpressure. The number 0.01 represents the conversion factor in the osmotic pressure term comes from a widely used rule of thumb for fresh and brackish water indicating that there is approximately 1 psi of osmotic pressure for every $100 \mathrm{mg} / \mathrm{L}$ of TDS. However, in many cases, the filtrate TDS concentration (TDS p) is small and can be neglected.

The concentration effect is characterized by the volumetric concentration factor (VCF), a dimensionless parameter representing the ratio of the concentration of suspended solids on the feed side of the membrane relative to that of the influent feed to the membrane filtration process, as shown in Equation 6:

$$
V C F=\frac{C_{m}}{C_{f}}
$$


Where: $V C F=$ volumetric concentration factor (dimensionless)

$C_{m}=$ concentration of suspended solids maintained on the feed side of the membrane (number or mass/volume)

$C_{f}=$ concentration of suspended solids in the influent feed water to the membrane system (number or mass/volume)

\subsubsection{Plug flow unit model}

Assumption of hydraulic configurations of membrane filtration systems

The term hydraulic configuration is used to explain the manner, where the feed water and suspended solids are processed by a membrane filtration system. The hydraulic configuration of a system is determined from operational conditions such as backwash, concentrate flow and recycle flow, where applicable. The considered hydraulic configuration mode is suspension mode (crossflow mode) ${ }^{[21-26]}$.

Three basic assumptions for the various hydraulic configurations in which membrane filtration systems can operate and present the associated equations used to determine the respective volumetric concentration factor (VCFs). :

If a hydraulic force tangential to the membrane surface is absent, suspended particles in the feed stream are deposited on the membrane and held in place by the TMP.

If a hydraulic force tangential to the membrane surface is found, significant suspended particles remain in suspension, providing in elevated concentrations of suspended particulate matter on the feed side of the membrane. Increasing concentration is characterized by the VCF, which can vary as a function of position and/or time for various hydraulic configurations.

The membrane is a complete barrier to the passage of the particulate contaminants assuming fully integral conditions.

Membrane filtration systems that operate as PFUs have a VCF that varies as a function of position in the system. The designed filtration systems include spiral-wound modules NF/RO systems and MF/UF systems connected in a continuous mode as shown in Figure 4.

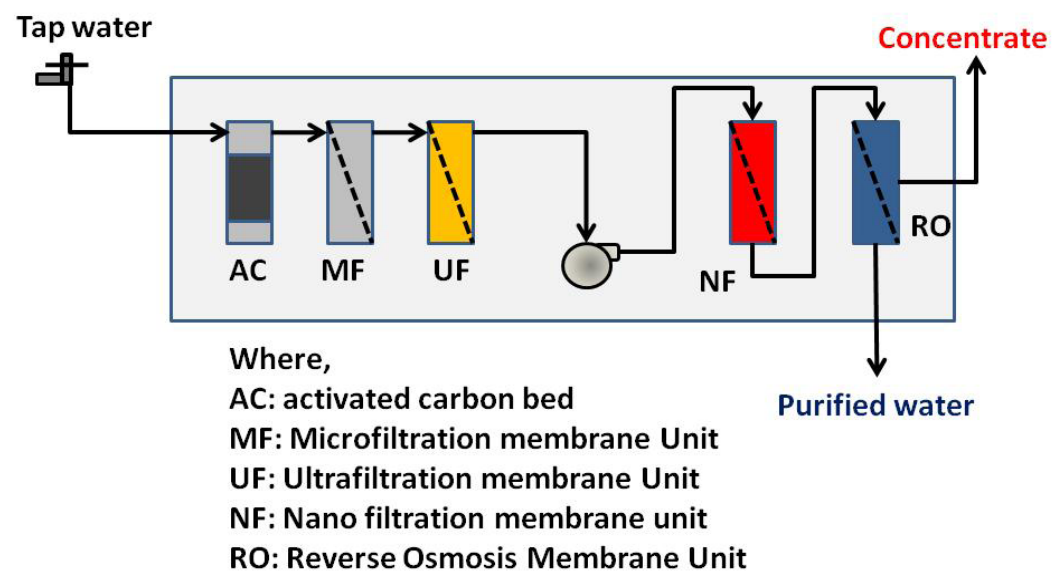

Figure 4. Flow Diagram for Plug Flow Units for filtration systems

The concentration of suspended solids on the feed side of the membrane in a PFU can be expressed as a function of the recovery at any position within the system, as shown in Equation 7:

$$
C_{m}(x)=\frac{C_{f}}{1-R(x)}
$$

Where: $C_{m}(x)=$ concentration on the feed side of the membrane at position $x$ in the membrane unit (number or mass/ volume)

$x=$ position in the membrane unit in the direction of tangential flow (i.e., $x=0$ at the entrance to the first module)

$\mathrm{C}_{f}=$ feed concentration at the inlet to the membrane unit (number or mass/volume)

$R(x)=$ recovery as a function of position within the membrane unit (decimal percent)

Equations 6 and 7 can be combined to create an expression for the VCF as a function of position in a PFU, as shown in Equation 8: 


$$
\operatorname{VCF}(x)=\frac{1}{1-R(x)}
$$

Where: $V C F(x)=V C F$ as a function of position in the membrane unit (dimensionless) $x=$ position in the membrane unit in the direction of tangential flow (i.e., $x=0$ at the entrance to the first module) $R(\mathrm{x})=$ recovery as a function of position within the membrane unit (decimal percent)

A flow-weighted average can be computed using numerical techniques, as shown in Equation $9^{[21]}$ :

$$
V C F(\operatorname{avg})=\frac{\sum\left[\operatorname{VCF}(x) * Q_{p}(x)\right]}{Q_{p}}
$$

Where: $V C F a v g=($ flow-weighted) average $V C F$ (dimensionless) $V C F(x)=V C F$ at discrete position " $x$ " within the membrane unit (dimensionless)

$x=$ position in the membrane unit in the direction of tangential flow (i.e., $x=0$ at the entrance to the first module)

$Q_{p}(x)=$ filtrate flow at position " $x$ " within the membrane unit $(\mathrm{L} / \mathrm{h})$

$Q_{p}=$ total filtrate flow from the membrane unit $(\mathrm{L} / \mathrm{h})$

Both the maximum and flow-weighted average VCFs (as calculated using Equations 8 and 9, respectively) for a typical NF/RO system over a range of overall system recoveries from 70 to 99 percent are summarized in Table 5 .

Table 5. Summary of VCF Values for NF/RO System Modeled as a PFU

\begin{tabular}{cccc}
\hline Recovery \% & Avg & VCF & Max \\
\hline 70 & 1.73 & 3.33 \\
75 & 1.86 & 5 \\
80 & 2.02 & 6.67 \\
85 & 2.25 & 10 \\
90 & 2.56 & 20 \\
95 & 3.16 & \\
\hline
\end{tabular}

Using standard area of NF and RO filter was $378.84 \mathrm{~cm}^{2}$, feed pressure was $145-250$ psi, filtrate pressure was approximately $138-210 \mathrm{psi}$, TMP was $7.2 \mathrm{psi}$ and flux was $26.4 \mathrm{~L} / \mathrm{m}^{2} . \mathrm{h}$. According to the commercial filtration unit size, the nanofiltration and Reverse osmosis unit have the same structure of commercial. The material of construction of housing was reinforced PVC.

The flat sheet membranes which were prepared were used in the fabrication of spiral wound membranes in size 29.85 cm length and $4.57 \mathrm{~cm}$ diameter to be the same size of commercial membranes in the market.

The spiral wound membrane is cylindrical configuration and it is considered essentially a flat-sheet, cross-flow device. The feedwater passes through the module axially, while permeate moves in the spiral, radial direction toward the permeate collection tube. Using spiral wound modules provides cost reduction but more often by the desire to extract the full value of the latest membrane technologies. There are five major non-membrane components of the spiral wound module as shown in Figure 5; Feed Spacer; Permeate Spacer and Permeate Tube. These components with membranes were rolled using machines as shown in Figure 6. 


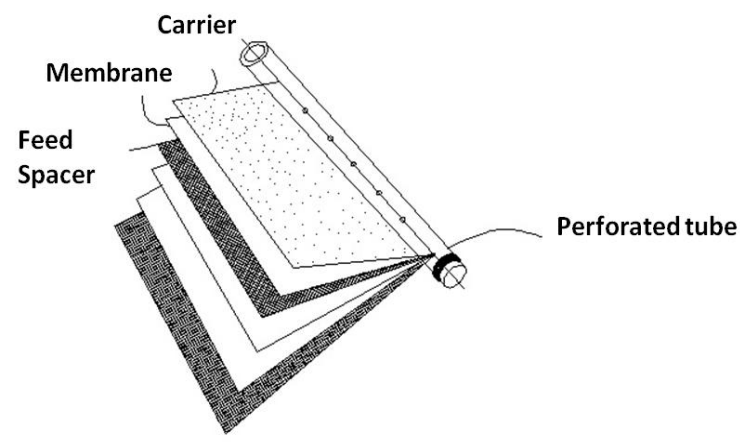

Figure 5. Elements of spiral wound modules

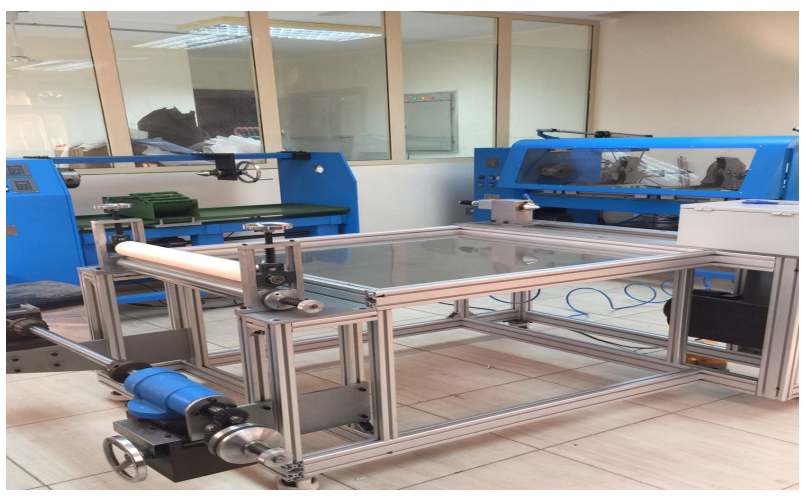

Figure 6. Spiral wound machines in NRC

\subsection{Comparison between commercial filtration system and integrated system}

Tap water from the Building of Scientific Excellence (NRC) was filtered using new integrated system, where the water flows through the activated carbon filter, microfiltration membrane, ultrafiltration membrane then nanofiltration and reverse osmosis membrane, where these membranes were prepared in our lab as shown in Figure 7. The commercial filter results indicated that TDS reached $51 \mathrm{mg} / \mathrm{L}$, while after an integrated filtration system with using nanofiltration and reverse osmosis membrane the TDS reached $0.95 \mathrm{mg} / \mathrm{L}$, which matched with the World Health Organization water quality standard.

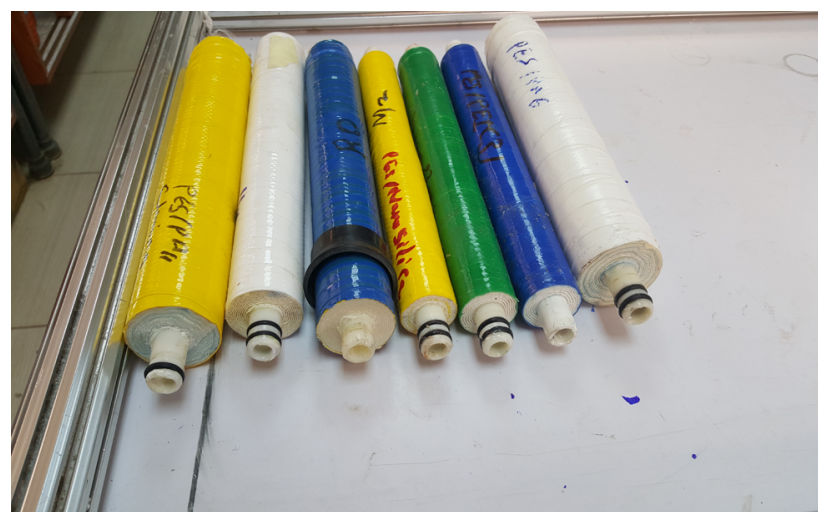

Figure 7. Prepared filters in NRC lab

\section{Conclusion}

Purified water is most important for some applications in industries and scientific application like medical, pharmaceuticals, cosmetics and chemical manufacturing which needs a special quality of treated water.

In this study, Water samples were collected from five locations of the National Research Centre; and analyzed to 
detect the most common problems in water and to determine the way for treatment.

Interrelationship studies was carried out between various water quality parameters to understand the geochemistry of the studied region of water.

The commercial filtration system was used to indicate the percentage of the element after each filtration step to facilitate the design of an integrated membrane system.

Design of five membrane systems was occurred to use our prepared membranes in the same standards of commercial membrane size to facilitate comparison between fabricated and commercial membranes.

The design model for system performance was studied assuming the model of the system is a plug flow model, where the calculated recovery reached to $95 \%$ using NF/RO membranes system.

Microfiltration polymeric membrane, ultrafiltration polymeric membrane, nanofiltration polymeric membrane and reverse osmosis polymeric membrane were prepared in NRC labs and were used in the designed integrated filtration system.

The integrated filtration system provides very low TDS for produced water reached $0.95 \mathrm{mg} / \mathrm{L}$ which matched with the World Health Organization water quality standard.

\section{References}

[1] Anthony Bennett, Clarity Authoring. Water processes and production of high and ultrapure water. Pumps \& Process Magazine. 2010; 67.

[2] ASTM (American Society for Testing and Materials) D1193-06, Standard Specification for Reagent Water. 2011.

[3] http://www.thermo.com/eThermo/CMA/PDFs/Various/File_52154.pdf [Accessed 22th February, 2013]

[4] Geetha A., Palanisamy P. N., Sivakumar P., Ganaeshkumar P., Sujatha M. E. Journal of Chemisty. 2008; 5(4): 696.

[5] Maiti S. K., Handbook of methods in environmental studies, Water and waste water analysis, ABD Publishers, Jaipur, Vol. 1(2004) Bhandari N. S., Kapil Nayal, E. Journal of Chemistry. 2008; 5(2), 342.

[6] Bayacioglu H. Water SA. 2006; 32(3): 389.

[7] Iyer C. S. Sindhu M. Kulkarni S. G. Tambe S. S., Kulkarni B. D. J. Environ. Monit. 2003; 5: 324.

[8] Mayur C. Shah, Prateek Shilpkar and Sangita Sharma. Asian J. Chem. 2007; 19(5): 3449.

[9] Mitali Sarkar, Abarna Banerjee, Partha Pratim Parameters and Sumit Chakraborty. J. Indian Chem. Soc. 2006; 83: 1023.

[10] Silvia Fernandez UnaiVillanveva, Alberto de Diego Gorka Arana and Juan manuel Madariaga. Journal of Marine systems. 2008; 72(4): 332.

[11] Korfali and Jurdi. Int. J. Environmental and Pollution. 2003; 19(3): 271.

[12] Khanna D. R., Singh S. Gautam A., Singh J. P. India J. Nat. Con. 2003; 15(1): 165.

[13] Dilli Rani G. Suman M. Narasimha Rao C. Reddi Rani P. Prashanth V. G. Prathibha R. and Venkateswarlu P. Current World Environment. 2011; 6(1): 191.

[14] Venkateswarlu P. Suman M. and Narasimha Rao C. Research. Journal of Pharmaceutical Biological and Chemical Sciences. 2011; 2(2): 464.

[15] Lining Ma, Xinfa Dong, Mingliang Chen, Li Zhu, Chaoxian Wang, Fenglin Yang and Yingchao Dong, Fabrication and Water Treatment Application of Carbon Nanotubes (CNTs)-Based Composite Membranes: A Review, Membranes. 2017; 7: 16. Available from: doi:10.3390/membranes7010016.

[16] Tong, T. Elimelech, M. The global rise of zero liquid discharge for wastewater management: drivers, technologies, and future directions. Environ. Sci. Technol. 2016; 50: 6846-6855.

[17] Wang, K. Abdalla, A.A. Khaleel, M.A. Hilal, N. Khraisheh, M. K. Mechanical properties of water desalination and wastewater treatment membranes. Desalination. 2017; 401: 190-205.

[18] Zhu, Z. Xiao, J. He, W. Wang, T. Wei, Z. Dong, Y. A phase-inversion casting process for preparation of tubular porous alumina ceramic membranes. J. Eur. Ceram. Soc. 2015; 35: 3187-3194.

[19] Das, R. Ali, M.E. Hamid, S.B.A. Ramakrishna, S. Chowdhury, Z.Z. Carbon nanotube membranes for water purification: A bright future in water desalination. Desalination. 2014; 336: 97-109.

[20] Goh, P.S. Ismail, A.F. Ng, B.C. Carbon nanotubes for desalination: Performance evaluation and current hurdles. Desalination. 2013; 308: 2-14.

[21] Steve Allgeier. Membrane Filtration Guidance Manual, United States Environmental Protection Agency. November 2005; EPA 815-R-06-009.

[22] Ming-Yong Zhou, Peng Zhang, Li-Feng Fang, Bao-Ku Zhu, Jian-Li Wang, Jiang-Hua Chen, Heba M. Abdallah. A positively charged tight UF membrane and its properties for removing trace metal cations via electrostatic repulsion mechanism. Journal of Hazardous Materials. 2019; 373:168-175. 
[23] M. Shaban, H. AbdAllah, L. Said1, Ashour M. Ahmed. Water desalination and dyes separation from industrial wastewater by PES/TiO2NTs mixed matrix membranes. Journal of Polymer Research. 2019; 26:181.

[24] Revathy Rajakumaran,Vinisha Boddu ,Mathava Kumar, Marwa S.Shalaby, Heba Abdallah, Raghuram Chetty. Effect of $\mathrm{ZnO}$ morphology on GO-ZnO modified polyamide reverse osmosis membranes for desalination. Desalination. 2019; 467:245-256.

[25] Grmek-Kosnik I, Ihan A, Dermota U, Rems M, Kosnik M, Jorn Kolmos H. Evaluation of separate vs pooled swab cultures, different media, broth enrichment and anatomical sites of screening for the detection of methicillin-resistant Staphylococcus aureus from clinical specimens. J Hosp Infect. 2005;61(2):155-61.

[26] J. Sambrook, E.F. Fritsch, T. Maniatis. Molecularcloning: a laboratory manual, cold spring harbor, N.Y.: Cold spring Harbor laboratory, 2001. 